Editorial

\title{
Urban Planning and the Suburbs: Solutions for Sustainability from the Edges
}

\author{
Markus Moos \\ School of Planning, University of Waterloo, Waterloo, N2L 3G1, Canada; E-Mail: markus.moos@uwaterloo.ca
}

Submitted: 22 October 2018 | Published: 30 October 2018

\begin{abstract}
This thematic issue of Urban Planning includes five articles that engage critically with the debates regarding the sustainability of suburbs. Contributions include a long-term perspective of the persistence of automobile-based planning and culture in Canada; an assessment of transportation modes among high-rise condominium apartment residents in Toronto's outer suburbs; an evaluation of policy prescribed social-mix in France's banlieues; a study of hyper-diversity in Peel Region in the Greater Toronto Area, which positions suburbs as centers of diversity; and an analysis of how the implementation and governance of new urbanist designs in three US communities has generally failed to achieve social objectives. The articles put into question the common approach of implementing suburban sustainability policy via urbanization and social mix. Together, the contributions point to the need for more stringent restrictions on automobile use, enhanced transit service in the suburbs, emphasis on bottom-up, community-driven policy-making, recognition of multiple dimensions of diversity, and strong political leadership to drive sustainability policy forward.
\end{abstract}

\section{Keywords}

planning; solutions; suburbs; sustainability

\section{Issue}

This editorial is part of the issue "Urban Planning and the Suburbs: Solutions for Sustainability from the Edges", edited by Markus Moos (University of Waterloo, Canada).

(C) 2018 by the author; licensee Cogitatio (Lisbon, Portugal). This article is licensed under a Creative Commons Attribution 4.0 International License (CC BY).

\section{Introduction}

In this thematic issue of Urban Planning authors engage with the debates regarding the long-term sustainability of suburbs in a critical manner. Specifically, the authors examine the potential of contemporary planning solutions to suburban sustainability concerns. In North America and many parts of Europe, planners regularly depict suburbanization, here broadly defined as peripheral growth, as inherently problematic, or in need of a 'sustainability fix'.

Suburbanization is seen as problematic as it traditionally produced sprawling and fragmented development patterns that are more energy intensive to service and connect. Because it often unfolds in large swaths of similar kinds of developments, suburbanization is also commonly associated with increasing social segregation.

Planning solutions to date have largely focused on urbanizing the suburbs by adding density and public tran- sit to reduce car reliance and land consumption, and by increasing social mix to enhance diversity. The question many of the articles in this thematic issue contemplate is whether, and how, these solutions have actually helped us make progress toward sustainability.

\section{Content}

In the first article, Pierre Filion (2018) tracks the enduring features of Canadian suburbs. He finds change in the form of new urban growth centers and densification but also consistency in terms of the influences of the automobile. The adaptations of the built form to the car, Filion argues, continue to influence all aspects of suburban life. Filion offers a somber yet important picture of the lack of influence planning for sustainability has had on aggregate metropolitan development and transportation patterns.

In Moos, Woodside, Vinodrai and Yan (2018) we consider one emerging form of suburban development, the 
high-rise condominium tower, traditionally associated with downtown redevelopment. In the case of Toronto, we show that suburban high-rise condo residents do have less automobile intensive commute patterns than other suburban residents, partly due to demographic transitions. Although the impacts remain limited, we see potential for the high-rise condo to reduce automobile use, and its negative environmental impacts, by improving transit service in the suburbs.

Juliet Carpenter's (2018) article focuses on social mix as sustainability policy in the French suburbs, or banlieues, which have a history of being marginalized. The work highlights the importance of giving voice to local communities about the future of their neighbourhoods. Social mix as a top-down policy, Carpenter argues, actually enhances social segregation by contributing to marginalization and displacement. She advocates for a bottom-up approach that includes local community members in deciding the future of their neighbourhoods.

In Dean, Regier, Patel, Wilson and Ghassemi (2018) we continue on the theme of social diversity, arguing for the benefits of considering suburban sustainability through the lens of 'hyper diversity'. They position suburbs, using a specific example from Peel Region in the Greater Toronto Area, as evident 'centers' of diversity and cultural pluralism in the 21st century metropolis. Dean et al.'s work illustrates the importance of planning for diversity that goes beyond the binary of inside versus outside ethnic enclave living. People's lives, they find, are intertwined with various dimensions of metropolitan forms and structures that exist in and outside of ethnic neighbourhoods.

Finally, Dan Trudeau's (2018) article brings into tension both the environmental and social equity aspects of sustainability. He considers the specific case of three new urbanist developments in the US. Trudeau considers the ways municipalities govern the implementation of new urbanist communities, and in doing so reinforce 'utopian' ideals of traditional suburban forms and cultures. He shows that while there are gains made in terms of environmental sustainability due to higher density developments, social equity objectives fall aside due to the ways in which new urbanist communities are implemented and sold.

\section{Further Development}

Although there are many solutions to sustainability concerns, dominant themes in planning literature and practice are the promotion of higher density urban forms and social mix. Hence, it is not unexpected that the articles in this thematic issue focus on these themes. While the perspectives may provide broad insight, we must remember that this collection consists of articles only from the global north that focus on specific countries and cities. Still, there are overarching pragmatic insights to take away from these articles that I see as key implementation points for planning practitioners and researchers to consider in their work:
1. Automobile-based development is enduring. If we are to reduce carbon emissions, automobile use needs to be challenged head-on by restricting driving and offering real alternatives;

2. Communities need a voice. Top-down approaches to achieving social objectives can actually further contribute to marginalization and displacement;

3. Top-down leadership is required. Although local communities need a voice, implementation requires leadership from politicians and government officials;

4. People and places do not fit neatly into single categories. Diversity needs to be considered in all its forms.

Several articles in this issue demonstrate the limits of current policies aimed at densifying the suburbs. There is no question that some densification is required to use resources more efficiently. But the urbanization approach is problematic because, a) it overlooks the vast area that current low-density suburbs constitute, raising questions about the time required to densify such a large number of neighbourhoods, and b) the increase in density has in many instances contributed to gentrification, not necessarily slowed the pace of suburban expansion elsewhere, and not necessarily reduced car-dependence as the articles in this issue demonstrate.

\section{Conclusion}

Perhaps it is time for researchers and practitioners to change gears to study new plausible suburban futures that are environmentally sustainable and socially equitable that go beyond urbanizing the suburbs. What would a bottom-up, 'made in the suburbs' solution to environmental sustainability concerns look like? What opportunities do the vast neighbourhoods of cul-desacs, lawns, and open-space provide in terms of building affordable housing, sub(urban) agriculture, native plant rehabilitation, or bee keeping? What possibilities does the single-detached home offers in terms of multi-generational living, infill, home-based work, or local businesses?

Readers are invited to consider these and related questions that could have application and relevance in their local context. I hope that the contributions in this thematic issue stimulate thinking for new ideas for suburban sustainability solutions, appropriately contextualized and critically examined, around the globe.

\section{Acknowledgments}

I would like to express my sincere gratitude to the authors, peer-reviewers, and the journal's staff and editor for helping to make this special issue possible. Thank you to all involved. 


\section{Conflict of Interests}

The author declares no conflict of interests.

\section{References}

Carpenter, J. (2018). 'Social mix' as 'sustainability fix'? Exploring social sustainability in the French suburbs. Urban Planning, 3(4), 29-37.

Dean, J., Regier, K., Patel, A., Wilson, K., \& Ghassemi, E. (2018). Beyond the cosmopolis: Sustaining hyperdiversity in the suburbs of Peel Region, Ontario. Urban Planning, 3(4), 38-49.
Filion, P. (2018). Enduring features of the North American suburb: Built form, automobile orientation, suburban culture and political mobilization. Urban Planning, 3(4), 4-14.

Moos, M., Woodside, J., Vinodrai, T., \& Yan, C. (2018). Automobile commuting in suburban high-rise condominium apartments: Examining transitions toward suburban sustainability in Toronto. Urban Planning, 3(4), 15-28.

Trudeau, D. (2018). Sustaining suburbia through New Urbanism: Toward growing, green, and just suburbs? Urban Planning, 3(4), 50-60.

\section{About the Author}

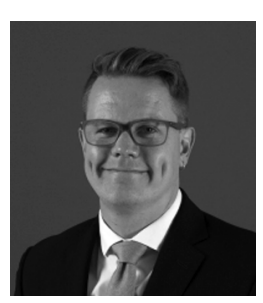

Markus Moos is Associate Professor in the School of Planning at the University of Waterloo. He is also a registered Professional Planner. His research is on the changing economies, social structures, housing markets and sustainability of cities and suburbs. 